\title{
Design and Implementation of GIS Data Production System for Expressway Video and Road Infostructure
}

\author{
Yuan Liu', Jianhua Liu1,2*, Guoqiang Feng1 \\ ${ }^{1}$ School of Geomatics and Urban Spatial Information, Beijing University of Civil Engineering and Architecture, Beijing, China \\ ${ }^{2}$ Key Laboratory for Urban Geomatics of National Administration of Surveying, Mapping and Geoinformation, Beijing, China \\ Email: *liujianhua@bucea.edu.cn
}

How to cite this paper: Liu, Y., Liu, J.H. and Feng, G.Q. (2021) Design and Implementation of GIS Data Production System for Expressway Video and Road Infostructure. International Journal of Geosciences, 12, 23-38.

https://doi.org/10.4236/ijg.2021.121003

Received: December 27, 2020

Accepted: January 26, 2021

Published: January 29, 2021

Copyright $\odot 2021$ by author(s) and Scientific Research Publishing Inc. This work is licensed under the Creative Commons Attribution International License (CC BY 4.0).

http://creativecommons.org/licenses/by/4.0/

\section{(c) (i) Open Access}

\begin{abstract}
The expressway is necessary for the development of the modern transportation industry, and the level of expressway construction reflects the overall grade of national or regional economic development. In order to process the expressway road property data information, based on the current mainstream Windows operating system, this study utilizes Geographic Information System (GIS) development technology, road video processing technology, and spatial data mining method to design and develop an expressway video and road infostructure GIS data production system. The system designs a multi-layer distributed application model in accordance with the ideas and methods of GIS engineering and the characteristics of road production data. In addition, according to the characteristics and specification requirements of basic geographic data, the road production database of spatial data and attribute data integrated storage is constructed by combining database and spatial data engine. Through the development of the GIS data production system for expressway video and road infostructure, various functions such as generation of road property data, dynamic management of road infostructure, and visualization of spatial information have been realized. The system focuses on improving the production efficiency and automation level of expressway production data and meets the construction requirements for modernization, informatization, and intelligence of expressways.
\end{abstract}

\section{Keywords}

Expressway, GIS, Road Infostructure, Video, Road Property Data

\section{Introduction}

For more than thirty years since China began to develop expressways, the coun- 
try's expressways had reached 150,000 kilometers by 2020, making them the largest expressway network in the world. With the continuous acceleration of China's expressway construction process, expressway road property data demonstrate more massive and complex characteristics [1]. Therefore, the highway data production systems at a general level have been unable to meet the needs of expressway construction; rather, they impose higher requirements on the measurement work in the process of highway construction [2]. Besides, the requirements of modernization, informatization, and intelligent management of expressways have also promoted the development of new expressway data production systems [3].

In recent years, GIS technology has been widely adopted, which is closely related to the expressway data production and information management. GIS spatial databases are used for real-time dynamic management of graphic data and attribute data, as well as mining data's deep connection, so as to realize standardized management and scientific decision-making of expressways [4]. This study addresses the requirements of information processing of road property data; gives full play to the spatial data organization capability, spatial information calculation capability, and geographic knowledge service capability of GIS [5]; and establishes a set of intelligent, efficient, and scientific expressway data production system, so as to improve the work efficiency, work quality and automation level of operators and help managers make informative and scientific decision-making [6].

The rest of this article is structured as follows: Section 2 presents the overall architecture of the expressway video and road infostructure GIS data production system. Section 3 describes the key technologies used in the system development. Section 4 discusses the functions and implementation of each module of the system. Finally, Section 5 offers the conclusion of the study as well as the outlook.

\section{System Architecture}

After investigation and analysis of the existing demands in expressway data production, this system is developed and implemented based on a GIS platform using Windows application development technology, while a relational database is used to store relevant data. The system aims to establish an expressway data production platform to realize such functions as road property data classification, video configuration management, video track fusion, video fusion cutting, and video problem checking and repair, so as to help field staff handle on-site data collection in a highly efficient and automatic manner.

The architecture of this GIS data production system for expressway video and road infostructure is shown in Figure 1, which can be mainly divided into four layers, i.e., infrastructure layer, data service layer, software service layer, and user layer. The basic information is collected through various hardware and devices in the infrastructure layer and stored in a database through data transfer. Production operators can organize the basic road property data and generate expressway GIS data after the data are processed. By analyzing the expressway GIS 


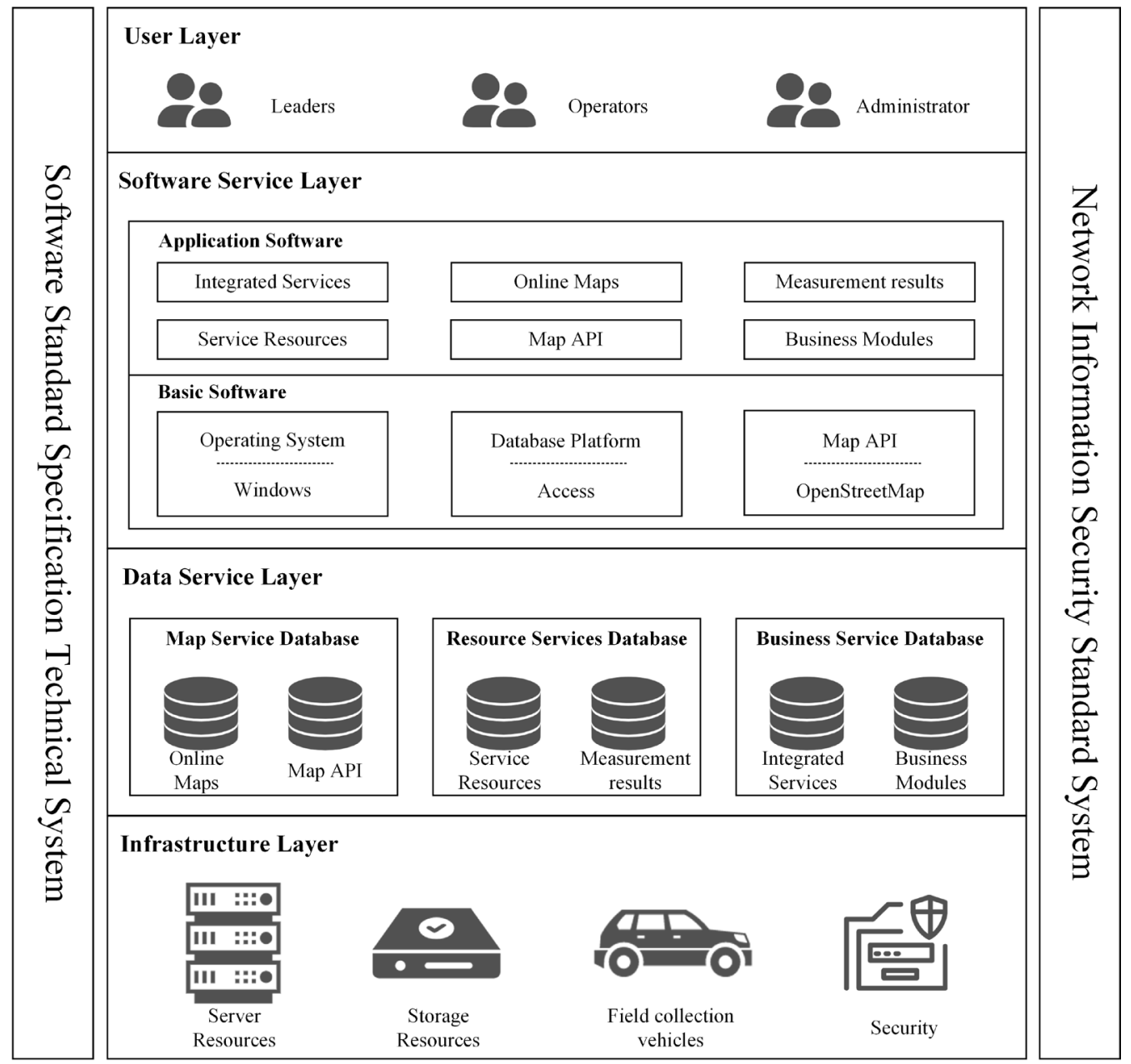

Figure 1. System architecture.

data, scheduling administrators can obtain the status of road infostructures and data collection errors promptly, thus facilitating the scheduling management. Leaders at all levels can use GIS knowledge service capability to deliver dynamic management and decision-making.

Through the design and development of multi-layer distributed architecture, this system is composed of expressway video GIS data production subsystem and road infostructure GIS data production subsystem. The system functional modules are shown in Figure 2. The main functions of the expressway video GIS data production subsystem include data configuration, track processing, video processing, and video restoration. The main function of the expressway road infostructure GIS data production subsystem is road property data processing and position offsetting.

\section{Key Technologies}

The GIS data production system for expressway video and road infostructure adopts the following components: .NET Framework 4.6.1 as the system development platform, WPF (Windows Presentation Foundation) interface design 


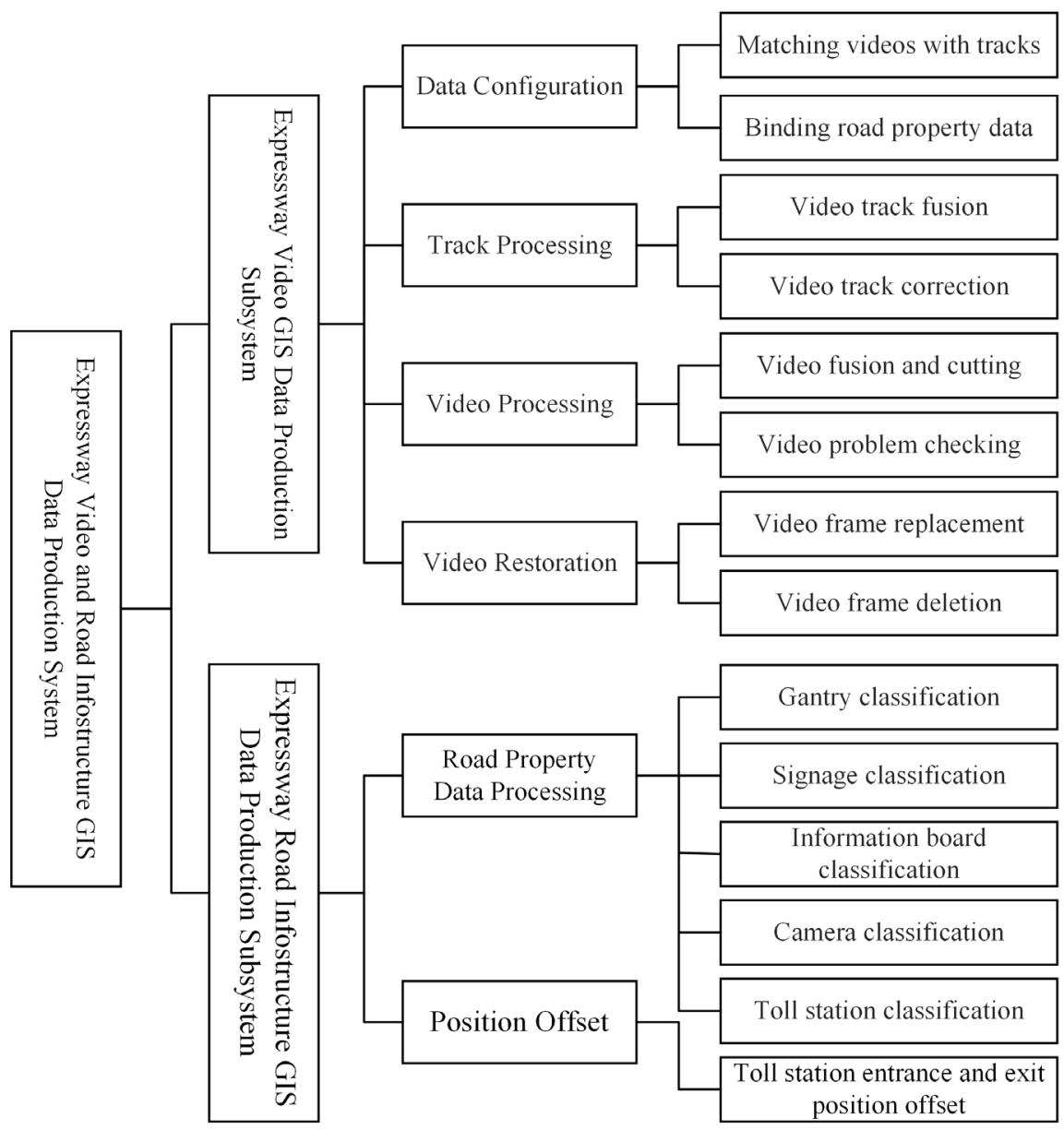

Figure 2. System function modules.

framework, Geodatabase data model, Access database management system, GIS secondary development component ArcGIS Engine, and Visual Studio 2019 as the integrated development environment. The key technologies involved include: Windows application development, GIS secondary development, spatial database, map service, video processing, etc.

\subsection{Windows Application Development}

WPF framework is the basis for the presentation of Windows applications and enables the separation of interface design and backend development, thus providing a multimedia interactive user graphical interface. Using XAML language to describe UI, WPF can implement complex elements through template nesting and realize business logic for data via a complete data binding mechanism, thus better separating data from the interface. The system also uses the MVVM (Model-View-ViewModel) pattern to develop WPF. The MVVM pattern adopts ViewModel to reduce the coupling between View and Model, i.e., to diminish the coupling between view interface and business logic, so as to cope with various complex changes in the requirements. The MVVM pattern's architecture is shown in Figure 3. 


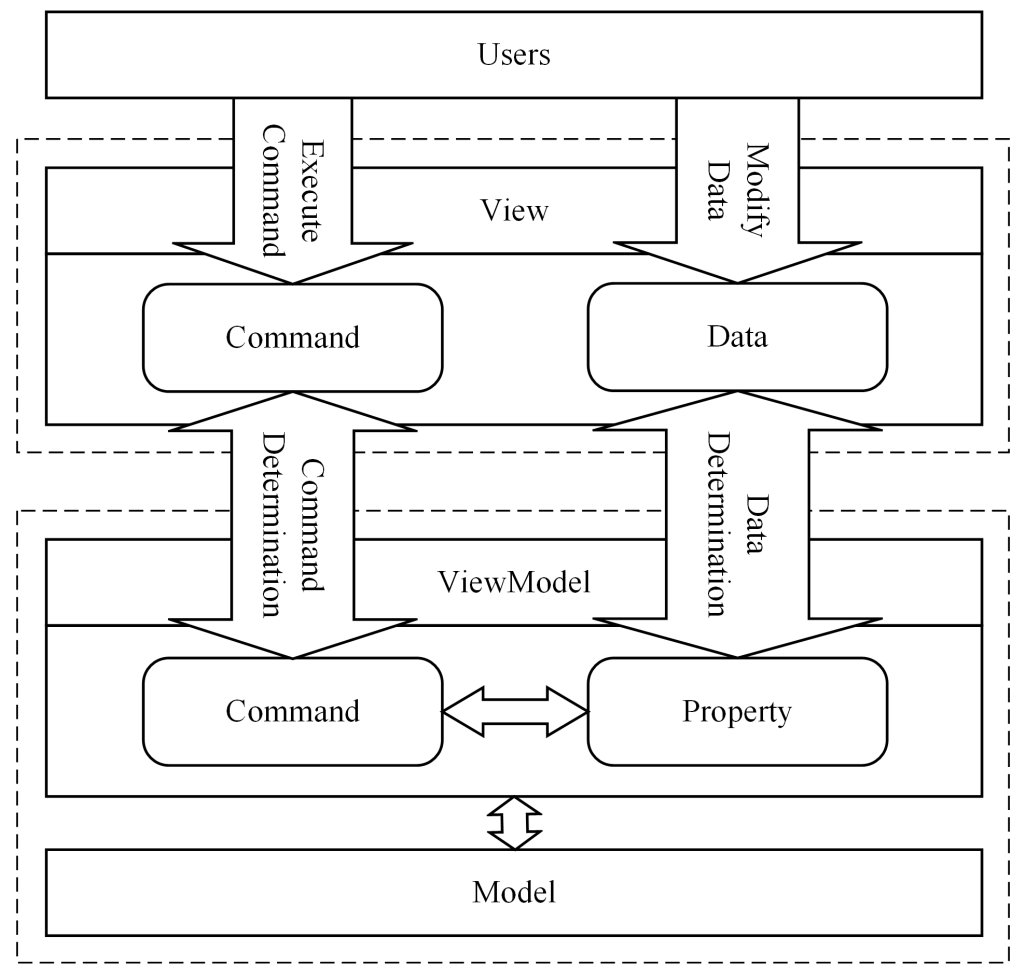

Figure 3. The MVVM pattern architecture.

\subsection{GIS Secondary Development}

GIS secondary development is purposed to develop applications for different objects based on the existing GIS software. Released by ESRI, ArcGIS Engine Development Kit is a component-based software development product and is the core function library for the entire ArcGIS software in building and deploying customized GIS and mapping applications. ArcGIS Engine consists of a development package and a runtime library with the core components required by GIS applications. It provides a wide range of data interfaces, including vector data, raster data, road infostructures for map creation, and thematic map capabilities. Based on the secondary development of GIS components, this system uses ArcGIS Engine to establish a basic map browser and a comprehensive and dynamic GIS editing tool. To meet the requirements of expressway road property data production, the system is further extended with ArcGIS Engine components and APIs to build more applications needed. The secondary development based on ArcGIS Engine can boost the development efficiency, while making the applications reliable and easy to transplant and maintain.

\subsection{Spatial Database}

The spatial database is the core of the GIS data production system for expressway video and road infostructure. Whether the design of the spatial database is efficient, stable, and secure would directly affect the development and applicability of the GIS data production system [7]. Proposed by ESRI, Geodatabase data model is a geographic data model that can be used for editing and managing da- 
ta. It organizes geographic data into data objects in a hierarchical manner, with its object hierarchy shown in Figure 4. Geodatabase data model realizes the unified storage of spatial data and attribute data, while providing a more intelligent representation of geospatial elements with better scalability [8]. Specifically, this system adopts the Personal Geodatabase of Geodatabase data model and uses Access database as its data storage medium.

For database-related operations, this system implements the Entity Framework, an Object Relation Mapping (ORM) framework proposed by Microsoft, much suitable for .NET development. Working between a business entity and a database, the Entity Framework can save data from entity properties to a database, retrieve data from the database, and automatically convert them into entity objects. And it can process data through .NET objects, without need to pay attention to the basic database that stores the data. By separating the database design from the domain object design, it makes programs more scalable and maintainable [9].

\subsection{Map Service}

Expressway road property data includes multimedia data, attribute data, vector data, etc. This system uses ArcGIS Engine to load map services on ArcGIS Server in the system. In this process, the connection attributes are set first, then a server connection workspace is created to obtain the server connection, later the name object is obtained according to the name of the data object, and finally the map service from the name object is acquired [10]. This system realizes the dynamic presentation of basic data and the generation of GIS road property data through map services.

\subsection{Video Processing Technology}

As an important part of expressway field survey results, video data contains the attribute information and spatial information about expressway main lines, and road infostructures. It plays an important role in the management and application

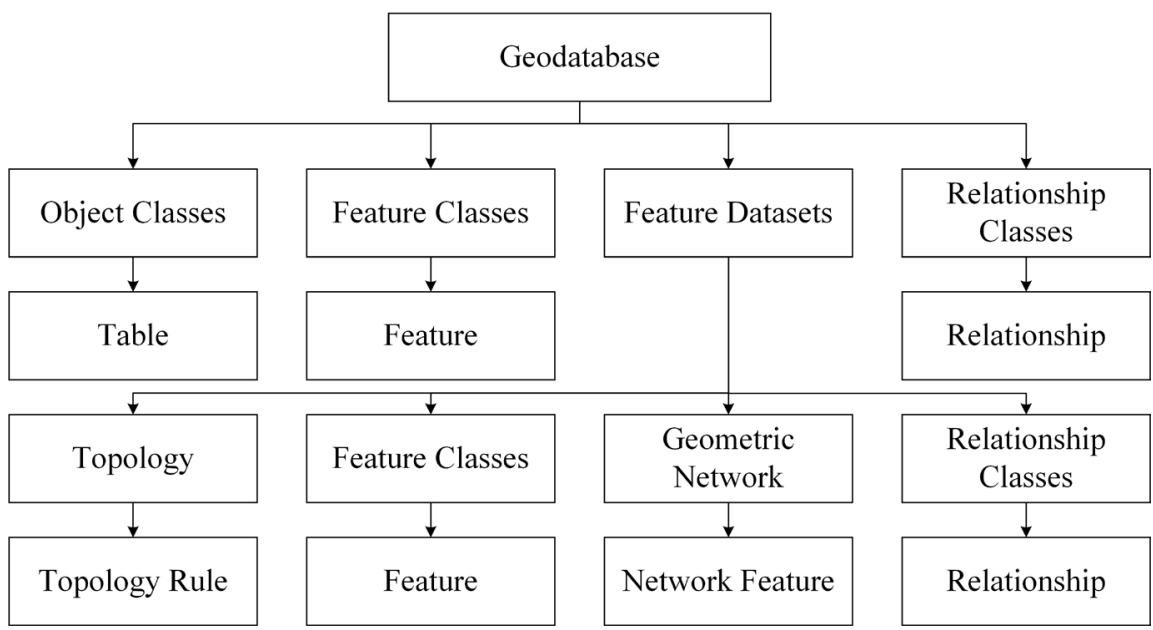

Figure 4. Object hierarchy of Geodatabase data model. 
of expressway property data. Therefore, video processing technology is critical for the expressway video GIS data production subsystem [11]. This system calls FFmpeg.NET bottom library to read, write, and process videos. FFmpeg is a set of open-source computer programs to record and convert digital audio and video into streams under the LGPL or GPL license. In this system, FFmpeg is used to encode, decode, separate, cut, and merge the video data collected by the expressway field collection vehicles. It can also capture real-time video streams, convert, and adjust videos at arbitrary sample rates [12].

\section{System Implementation}

The GIS data production system for expressway video and road infostructure is tailored to the application requirements of the intelligent transportation era. By processing expressway data such as navigation data, video data, and road vector data, it forms a system that can carry out daily management, rapid update, and intelligent processing of expressway GIS data. The GIS data production system for expressway video and road infostructure consists of two subsystems: The video GIS data production subsystem completes video data processing, tracks fusion, and makes other operations; and the road infostructure GIS data production subsystem transfers the post-processed of road property data into the library.

\subsection{Expressway Video GIS Data Production Subsystem}

The expressway video GIS data production subsystem mainly includes the function modules for video configuration management, track processing, and video processing. By establishing the video GIS data production subsystem, this study realizes the intellectualization and standardization of the corresponding binding between expressway videos and facilities along the line, track fusion and correction, video fusion and inspection.

\subsubsection{Video Configuration Management}

The purpose of video configuration management is to determine the correspondence between different groups of video files and track files and the road, ramps, toll stations, entrances, and exits, as well as the observation position. The technical flow of the video configuration management module is shown in Figure 5. Operators can import the list of field data collected into the system; manually bind and unbind video files and specific toll stations, service areas, and ramps through video playback and map synchronization tracks; and then determine whether each group of videos originates from the left-, right- or front-view camera. Each collection forms an engineering record of video files bound to structures and routes are stored in the database. The system interface for the video configuration management module is shown in Figure 6.

\subsubsection{Track Fusion and Correction}

Expressway videos are taken by the left, right, and front cameras. This module 


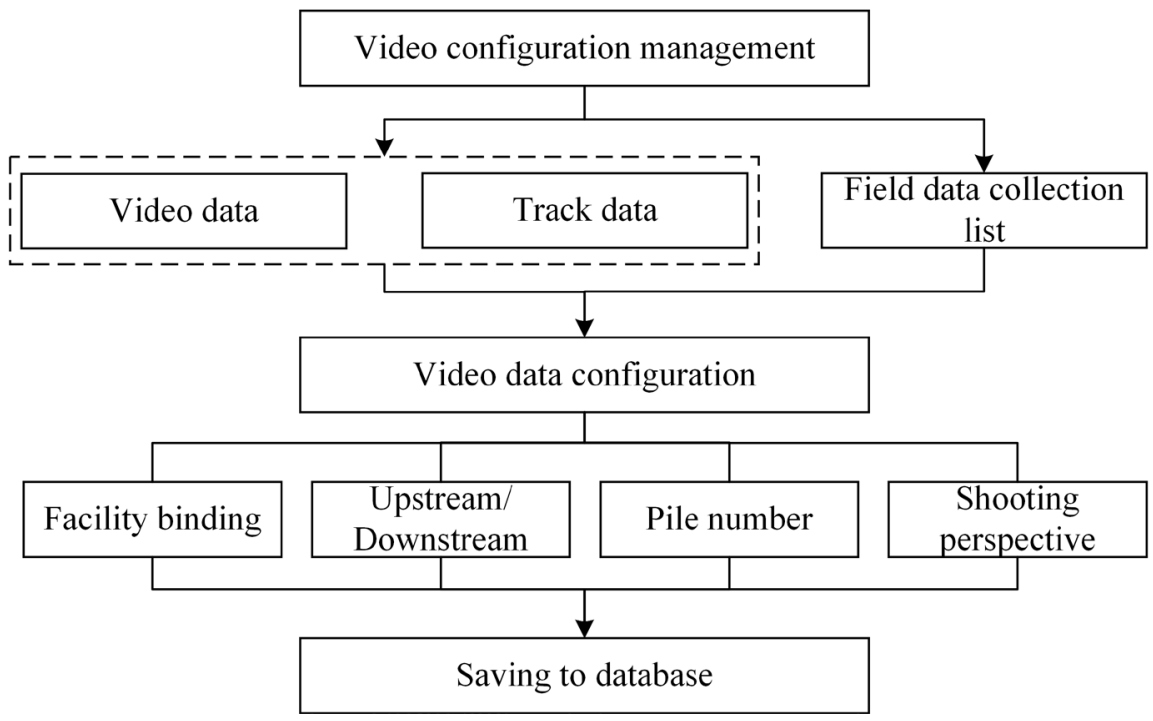

Figure 5. Video configuration management flowchart.

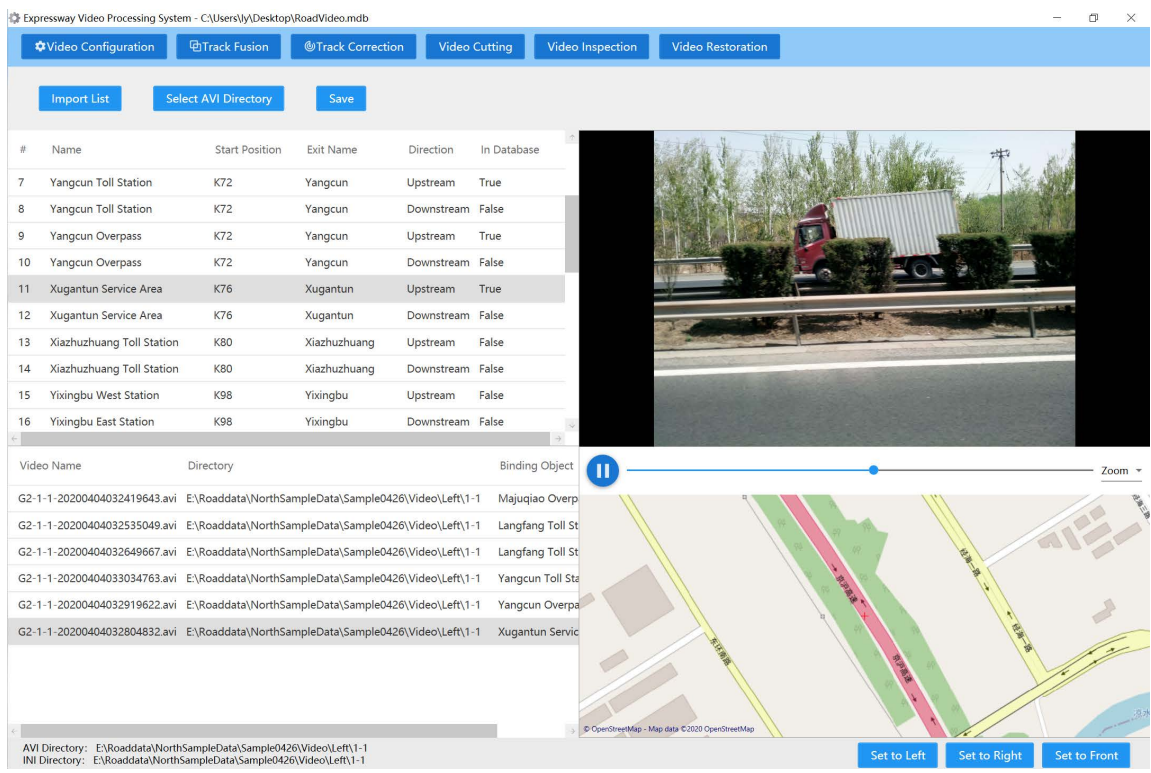

Figure 6. Video configuration management interface.

merges the tracks taken by the three cameras into one track. During fusion, the points where the error of a single camera exceeds the limit are eliminated, and the time points of photos and tracks are unified according to real videos and time phases of GPS acquisition points. Use road data to correct for large error overrun tracks that occur in such areas as tunnels and bridges. The flow of the track fusion and correction module is shown in Figure 7.

Operators can fuse the tracks under each field project by a rule using the field project, the road layer referenced by the project, the road number, and the list of track check questions. The track files from the three shots of each project are first readout; then the time points at which the three devices acquired the GPS tracks are checked, and finally, a uniform time series is formed in a chronological 


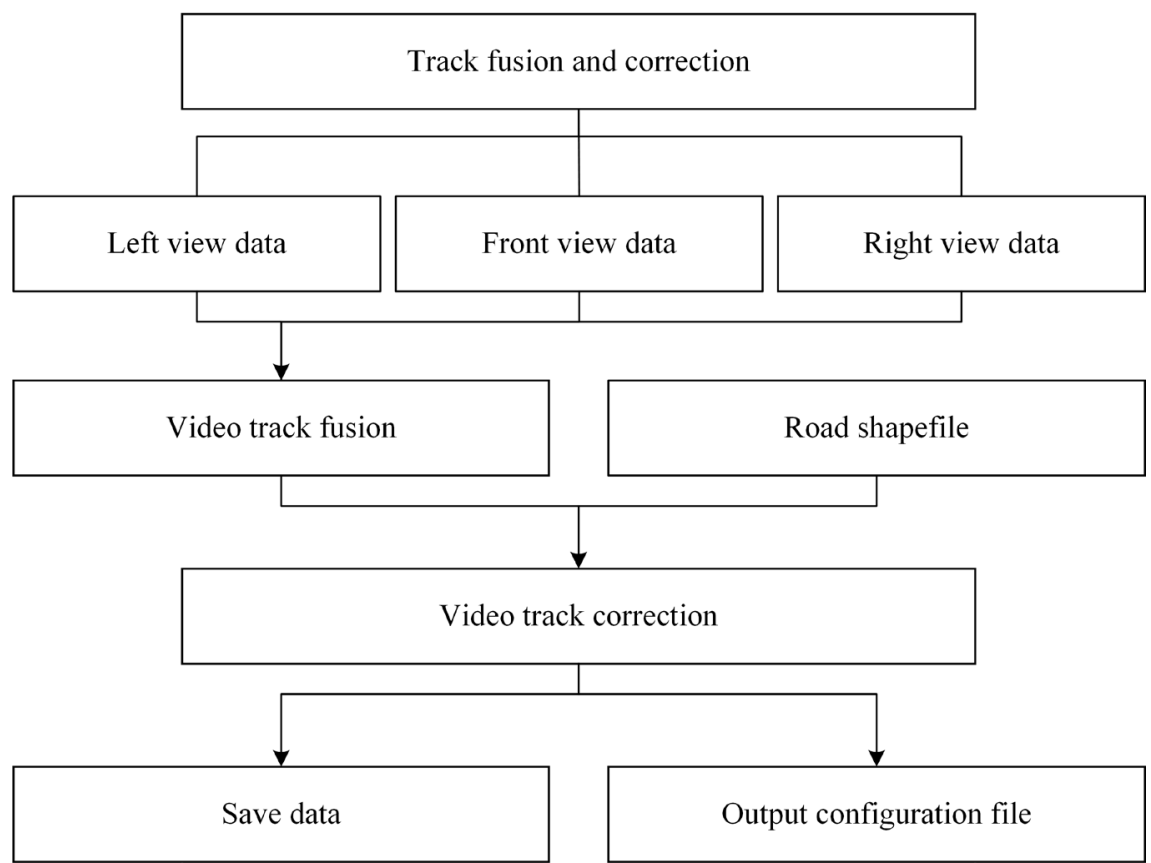

Figure 7. Track fusion and correction flowchart.

order. Then check the track file of each device according to the unified time series, and mark the time point as the acquisition point or interpolation point. At last, the system compares the three-track files, takes the average value of the acquisition points and interpolation points at the same time point as the coordinates of the time point, and connects the corresponding photos and shooting angles of each point, as well as the corresponding route number, travel direction, and pile number or structure number according to the configuration file. The interface of this module is shown in Figure 8.

\subsubsection{Video Fusion and Cutting}

The video fusion and cutting module can splice and merge multiple videos, and then cut out for interchange ramps, service areas, tunnels, bridges, and toll stations based on the range of the starting and ending points. The flow of this module is shown in Figure 9. Operators can read the data configuration of the database and combine the video files and the road layers to fuse and splice multiple videos. Then the overlapping parts and the parts beyond the route after video fusion are cut. Besides, in combination with the dynamic track of maps, the starting and ending points can be manually selected from the road layers for cutting preview and video output. The interface of the video fusion and cutting module is shown in Figure 10.

\subsubsection{Video Inspection and Restoration}

The video inspection and restoration module is purposed to check problems and control the quality of video data. This system automatically inspects whether a video has lost frames, stopped frames, etc., and then import quality control files to provide a basis for later quality processing. The individual frames from the 


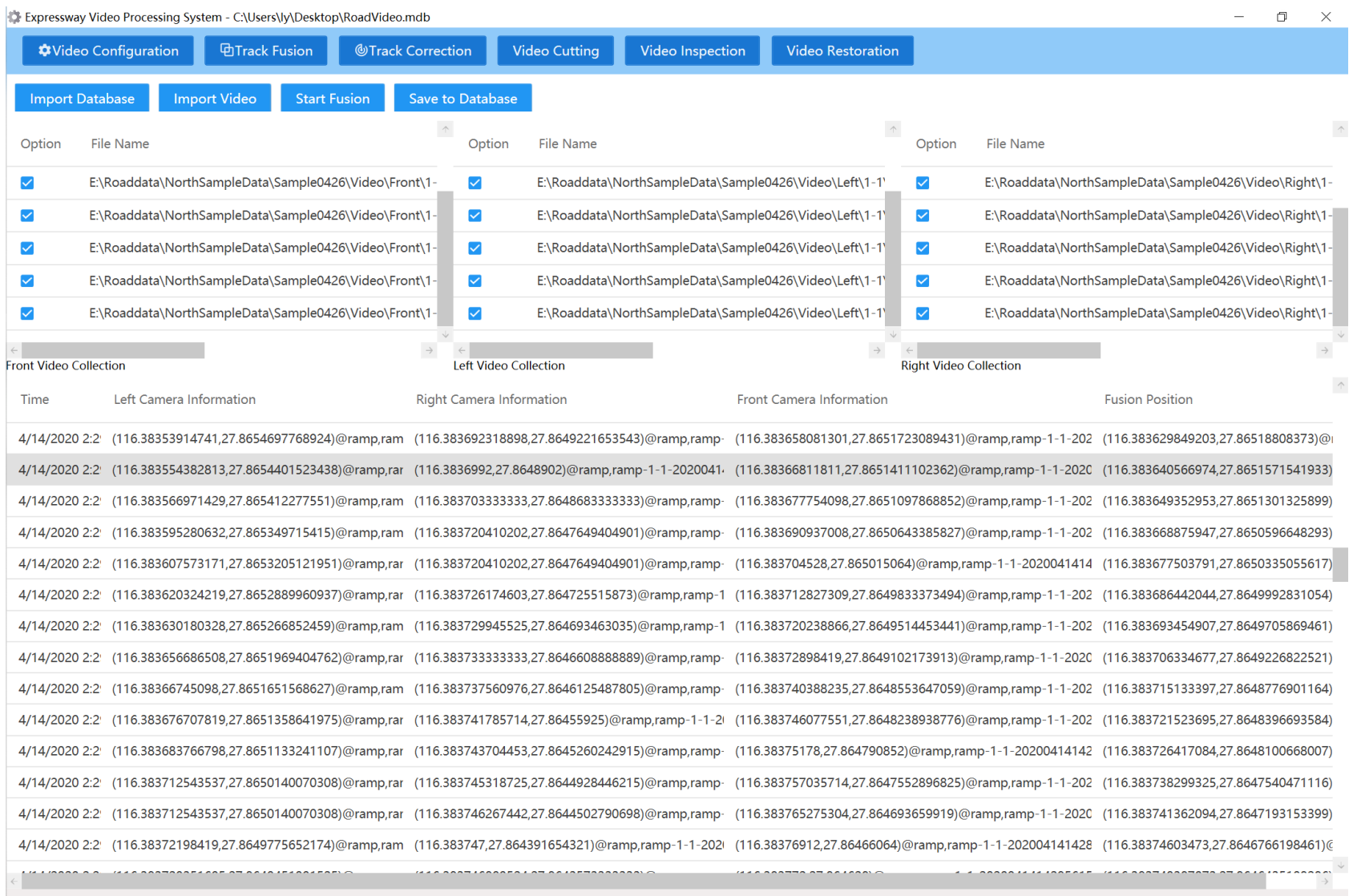

Figure 8. Track fusion and correction interface.

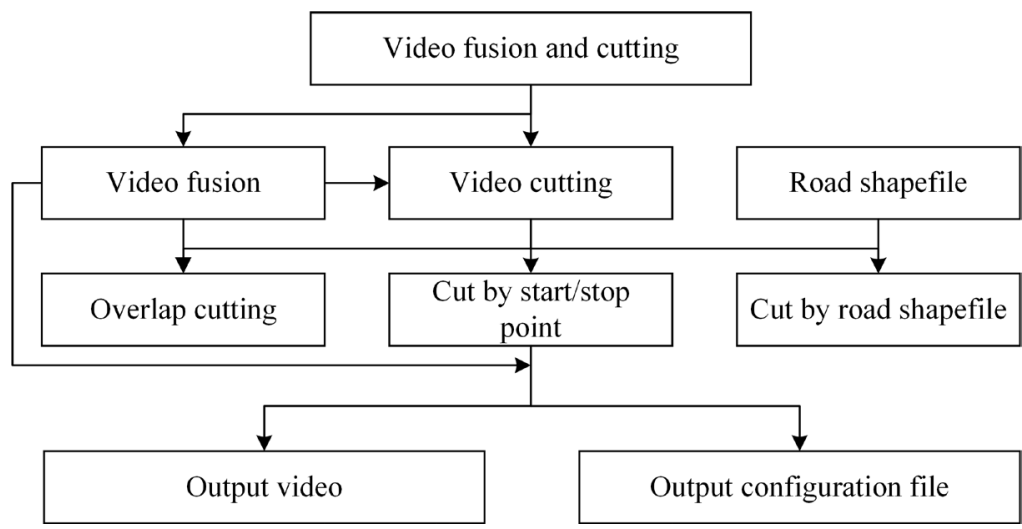

Figure 9. Video fusion and cutting flowchart.

complementary project are then inserted and replaced with the original video according to the inspection log, and the stop-frame and reverse-frame videos are removed with their GPS tracks before the videos are outputted. The flow of the video inspection and restoration module is shown in Figure 11.

Operators can import the video problem checklist and compare it with the error information contained in the video files resulting from the system check. Then, operators check or correct the checklist and re-upload and save it in the database. Finally, the video errors are fixed in frames according to the check 


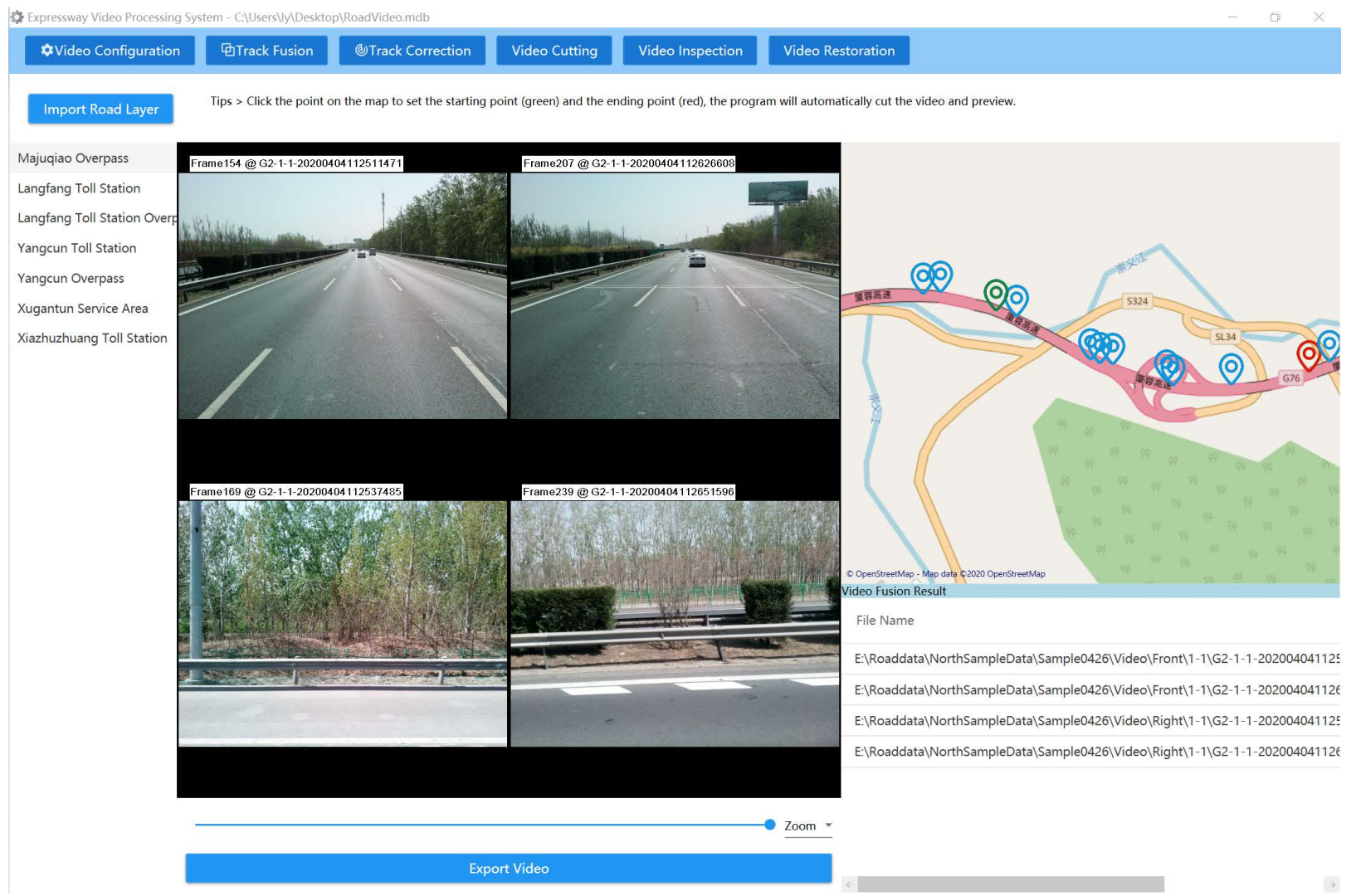

Figure 10. Video fusion and cutting interface.

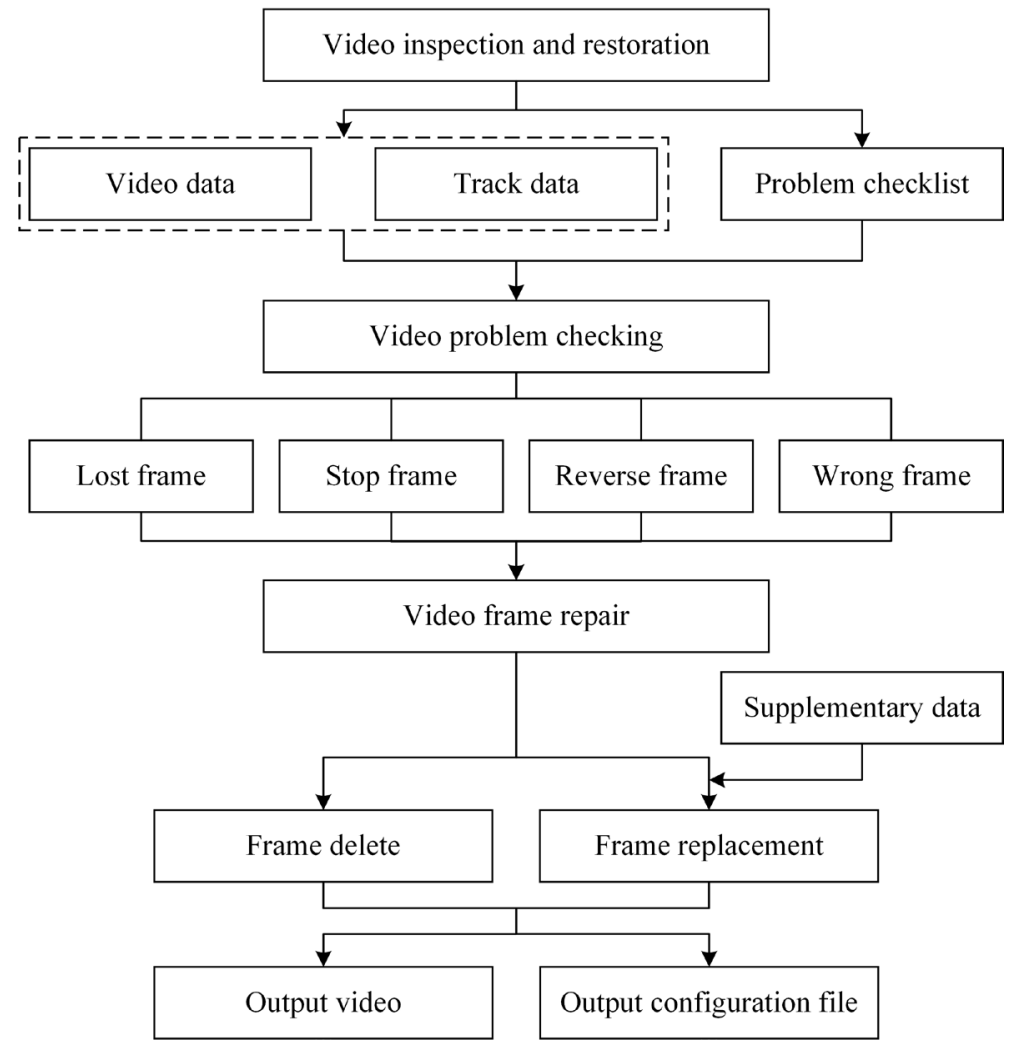

Figure 11. Video inspection and restoration flowchart. 
records. For the lost frames and wrong frames, the complementary videos and complementary tracks are selected to retrieve the video frame segments in the same or adjacent positions of the complementary videos on the basis of the shooting time, and locations of the problematic videos listed in the check question. Then, the original picture is replaced, and the track points and shooting time of the newly inserted videos are configured in the database; finally, the replaced videos and track files are outputted. For the problems of stop-frames and reverse frames, the wrong frame segments and tracks are deleted according to the video information in the check record table. At last, the repaired files are outputted. The interface of the video inspection and restoration module is shown in Figure 12.

\subsection{Expressway Road Infostructure GIS Data Production Subsystem}

The expressway road infostructure GIS data production subsystem takes gantries, signages, variable information boards, electromechanical facilities, and toll station entrances and exits as the main management objects, so as to realize refined and dynamic management of expressway road infostructures by separating various components from road property data, editing attributes, and saving data. The expressway road infostructure GIS data production subsystem mainly covers the functions for processing of road property data as well as toll stations' entrance and exit position offset.

\begin{tabular}{|c|c|c|c|c|c|c|c|}
\hline \$Video Configuration & फTrack Fusion & (C)Track Correction & Video Cutting & Video Inspection & \multicolumn{3}{|c|}{ Video Restoration } \\
\hline Import Other Videos & Import Checklist & & & & & & \\
\hline \multicolumn{2}{|l|}{ Video File List } & \multicolumn{3}{|l|}{ Video Narne } & Frame Number & Error Type & Detailed reasons \\
\hline \multirow{2}{*}{$\begin{array}{l}\text { G2-1-1-20200404112356454 } \\
\text { G2-1-1-20200404112511471 }\end{array}$} & & \multicolumn{3}{|c|}{ E:|Roaddata|NorthSampleData|Sample0426|Video|Front|1-1|G2-1-1-202004t } & 50 & Lost Frame & Time difference from the previous frame: 337 Milliseconds \\
\hline & & \multicolumn{3}{|c|}{ E:|Roaddata|NorthSampleData|Sample0426|Video|Front|1-1|G2-1-1-202004l } & 130 & Lost Frame & Time difference from the previous frame: 355 Milliseconds \\
\hline \multirow{2}{*}{$\begin{array}{l}\text { G2-1-1-20200404113011687 } \\
\text { G2-1-1-20200404112742612 }\end{array}$} & & \multicolumn{3}{|c|}{ E:Roaddata|NorthSampleData|Sample0426|Video|Front|1-1|G2-1-1-2020041 } & 170 & Lost Frame & Time difference from the previous frame: 372 Milliseconds \\
\hline & & \multicolumn{3}{|c|}{ E:Roaddata|NorthSampleData|Sample0426|Video|Front|1-1|G2-1-1-202004i } & 210 & Lost Frame & Time difference from the previous frame: $370 \mathrm{Milliseconds}$ \\
\hline \multicolumn{2}{|l|}{ G2-1-1-20200404112856684 } & E:|Roaddata \NorthSampleData & ample0426|Video|F & $t|1-1| G 2-1-1-202004$ & 250 & Lost Frame & Time difference from the previous frame: 376 Milliseconds \\
\hline \multicolumn{2}{|l|}{$\begin{array}{l}\text { G2-1-1-20200404112626608 } \\
\text { G2-1-1-20200404032419643 }\end{array}$} & E:|Roaddata $\backslash$ NorthSampleData & ample0426\VideolF & $n t 11-1 \backslash G 2-1-1-202004$ & 290 & Lost Frame & Time difference from the previous frame: $386 \mathrm{Milliseconds}$ \\
\hline \multicolumn{8}{|l|}{ G2-1-1-20200404032535049 } \\
\hline \multicolumn{8}{|l|}{ G2-1-1-20200404032649667 } \\
\hline \multicolumn{8}{|l|}{ G2-1-1-20200404033034763 } \\
\hline \multicolumn{8}{|l|}{ G2-1-1-20200404032919622 } \\
\hline \multicolumn{8}{|l|}{ G2-1-1-20200404032804832 } \\
\hline \multicolumn{8}{|l|}{ G2-1-1-20200404112922078 } \\
\hline \multicolumn{8}{|l|}{ G2-1-1-20200404112806643 } \\
\hline \multicolumn{8}{|l|}{ G2-1-1-20200404112421573 } \\
\hline \multicolumn{8}{|l|}{ G2-1-1-20200404112537485 } \\
\hline \multicolumn{8}{|l|}{ G2-1-1-20200404112651596 } \\
\hline \multicolumn{8}{|l|}{ G2-1-1-20200404113036606 } \\
\hline$-1-1-20200404112922078$ & -Ec & & & & & & \\
\hline
\end{tabular}

Figure 12. Video inspection and restoration interface. 


\subsubsection{Road Property Data Processing}

Expressway road property data include two types: the single road property, such as signages, information boards, cameras, and other facilities; and the composite road property, such as gantries and toll stations, which includes several single road property facilities. To process an item of composite property, operators should import the point element data and photo data for the property, and then edit the property attributes and save the data. Besides, the data about composite road property containing other facilities' information would require the component separation operation. Specifically, the operation is to take screenshots of the component facilities within composite road property photos, and then save the component pictures, element data, and attribute data to the database. Operators will obtain separate signages, information boards, and cameras when collecting expressway infostructure, with separate attribute editing and data storage for such data. Figure 13 shows the workflow of the road property data processing. Figure 14 illustrates the interface of road property data processing with a gantry as an example.

\subsubsection{Toll Stations' Entrance and Exit Position Offset}

Among the data collected in the field, the toll stations' entrance and exit data, toll station point data, and road data will shift according to the site conditions; and operators need to correct the deviation of the toll stations' entrance and exit position. According to the toll station data for buffer-zone analysis, operators select the toll stations' entrance and exit data within one hundred meters from

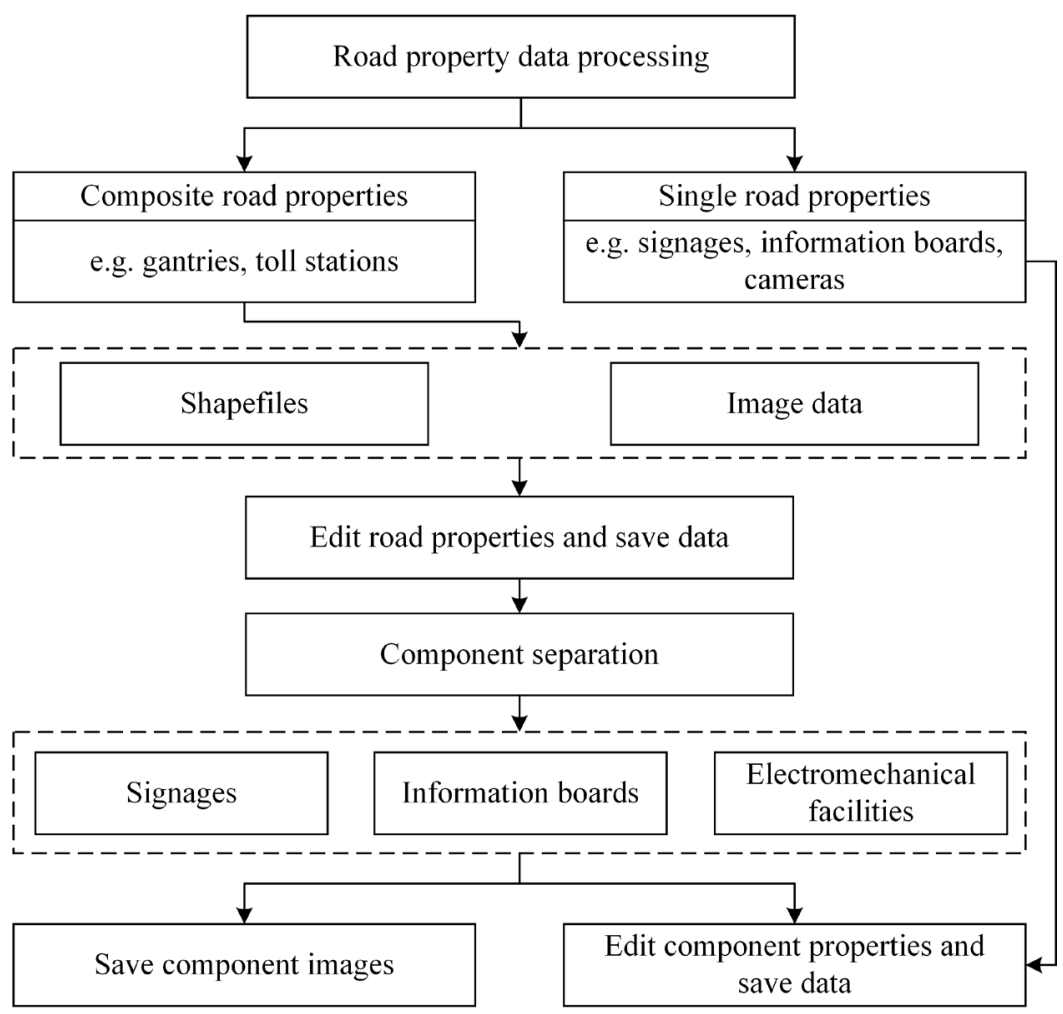

Figure 13. Road property data processing flowchart. 


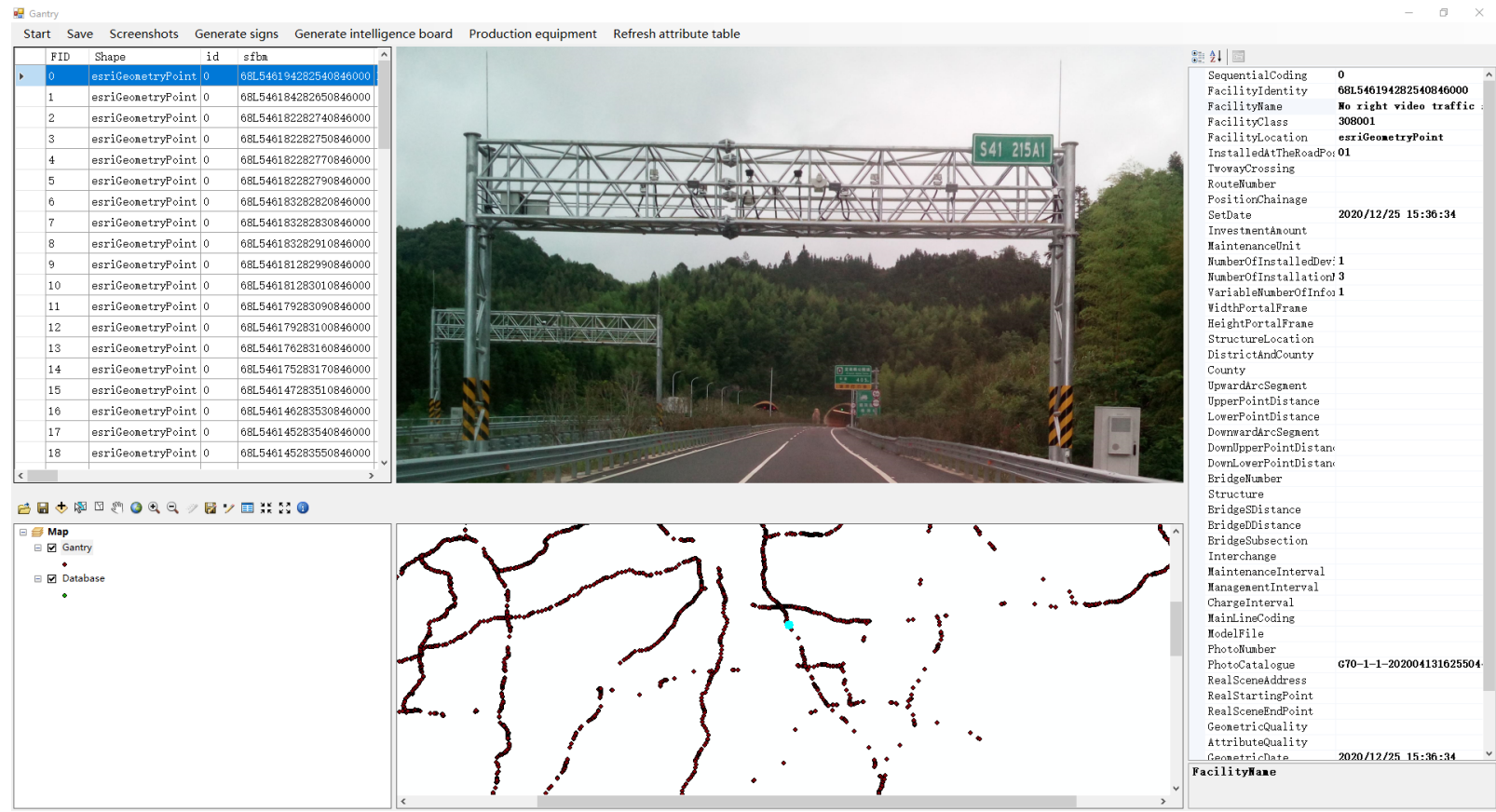

Figure 14. Gantry road property data processing interface.

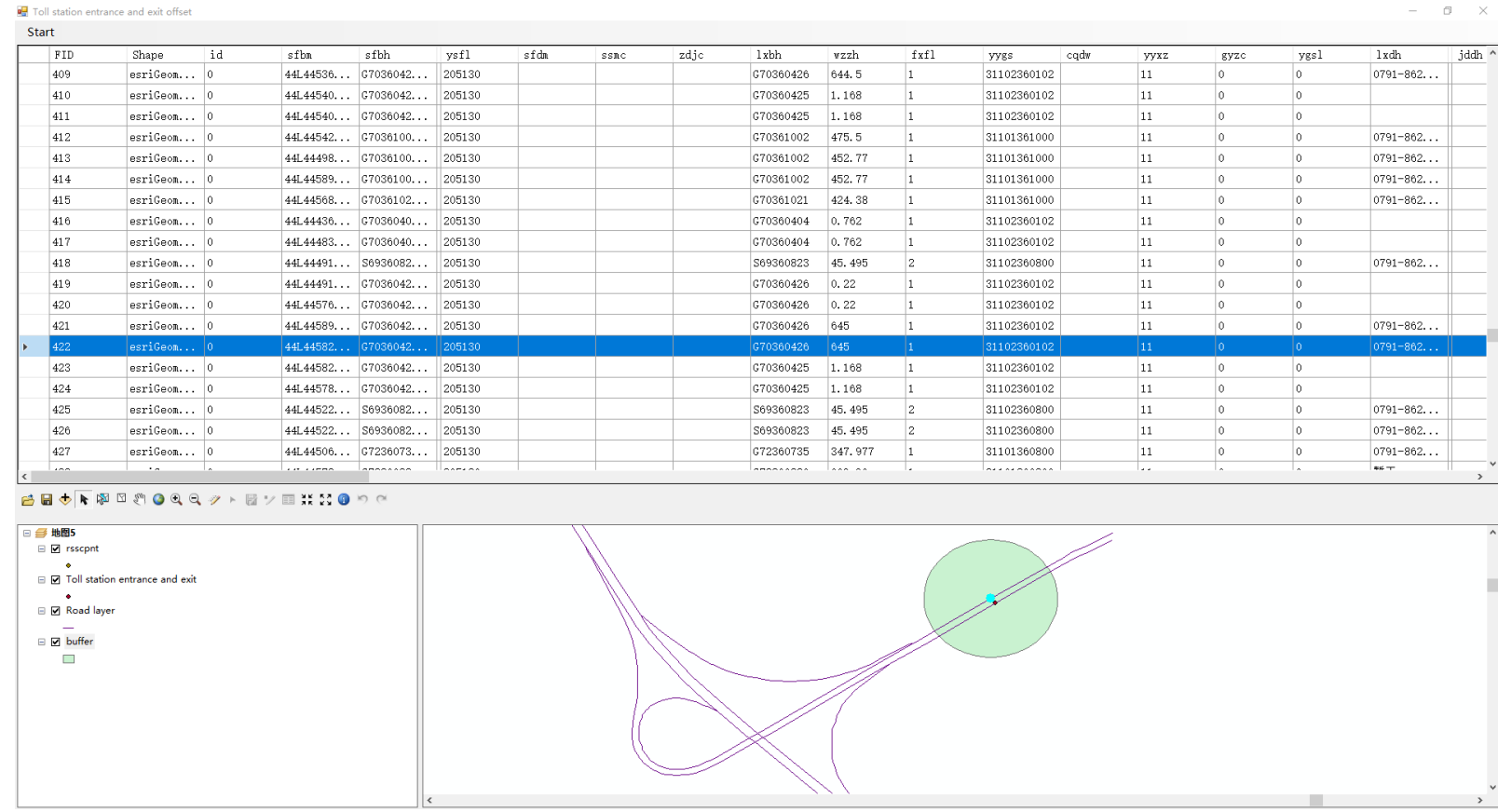

Figure 15. The interface of toll stations' entrance and exit position offset.

the station for attribute modification and manual position correction, and finally save the corrected data. Figure 15 shows the interface of toll stations' entrance and exit position offset.

\section{Conclusions}

As the major infrastructure for national economic and social development, ex- 
pressways have a growing demand for information construction. With a wide range of expressway data sources and a large amount of information, how to synthesize application analyses and present system functions intuitively and conveniently becomes a focus of the current research. By using GIS technology to achieve integrated management of expressways with massive storage data and powerful graphical operations, it is possible to provide timely and convenient access to the information on expressway road infostructures, so as to deliver more scientific and transparent expressway construction and management. By taking the unique advantages of GIS and spatial data mining methods, this study designs and implements GIS data production system for expressway video and road infostructure. This system realizes an automated mechanism for processing and producing data on expressway road property, and it can easily manage the road data processing operations in a timely and effective manner.

The functions of this GIS data production system for expressway video and road infostructure cover all aspects of processing and production the expressway video data and road infostructure data. This system has already gone live, and is running stably with effective functions. It improves the processing capability of expressway data production and provides a powerful tool for scientific decision-making by highway management departments. In the future, the research on spatial information mining and analysis will be further strengthened, and the current system's inherent advantages will be leveraged to promote the integration between expressway data resources and construction management.

\section{Acknowledgements}

This research is funded by the National Natural Science Foundation of China (No. 41301489), Beijing Natural Science Foundation (No. 4192018, No. 4142013), Outstanding Youth Teacher Program of Beijing Municipal Education Commission (No. YETP1647, No. 21147518608), Outstanding Youth Researcher Program of Beijing University of Civil Engineering and Architecture (No. 21082716012), the Fundamental Research Funds for Beijing Universities (No. X18282, No. X20099, No. X20077) and the BUCEA Post Graduate Innovation Project (No. PG2020078).

\section{Conflicts of Interest}

The authors declare no conflicts of interest regarding the publication of this paper.

\section{References}

[1] Li, J., Muench, S.T., Mahoney, J.P., Sivaneswaran, N., Pierce, L.M. and White, G.C. (2005) The Highway Development and Management System in Washington State: Calibration and Application for the Department of Transportation Road Network. Transportation Research Record, 1933, 52-61. https://journals.sagepub.com/doi/10.1177/0361198105193300107

[2] Gong, Y. and Liao, J. (2019) Big Data Platform for Urban Intelligent Transport Based on Block Chain Technology and Simulation Case Analysis. Journal of High- 
way and Transportation Research and Development, 36, 117-136.

https://kns.cnki.net/kcms/detail/detail.aspx?dbcode=CJFD\&dbname=CJFDLAST20 20\&filename $=$ GLJK201912015\&v=NUygrQms\%25mmd2FkLisHKe5lfCowVnB7DK UUJPSKS6RJcC0qGQTSJVdVXYthBS4lm1MsLm

[3] Huang, Y., Fang, D., Tan, F., Tao, M., Si, D. and Shu, Y. (2020) Research on Vehicle Trajectory Tracking Control in Expressway Maintenance Work Area Based on Coordinate Calibration. IOP Conference Series: Earth and Environmental Science, 619, 12096. https://iopscience.iop.org/article/10.1088/1755-1315/619/1/012096

[4] Zuidgeest, M., Brussel, M. and Maarseveen, M.F.A.M. (2015) GIS for Sustainable Urban Transport. ISPRS International Journal of Geo-Information, 4, 2583-2585. https://doi.org/10.3390/ijgi4042583

[5] Li, X., Lv, Z., Hu, J., Zhang, B., Yin, L., Zhong, C., et al. (2015) Traffic Management and Forecasting System Based on 3D GIS. 15th IEEE/ ACM International Symposium on Cluster, Cloud and Grid Computing, Shenzhen, 4-7 May 2015, 991-998. https://ieeexplore.ieee.org/document/7152585

[6] Ma, J. and Sun, L. (2001) Research on the Data Management of Urban Road Pavement Management System Based on GIS. China Journal of Highway and Transport, S1, 56-60.

https://kns.cnki.net/kcms/detail/detail.aspx?dbcode=CJFD\&dbname=CJFD2001\&fil ename=ZGGL2001S1014\&v=YFZDYh7PygnIumQS64eQVkIy4BQCqaAXWAGdfN QDP3iATflx\%25mmd2Budz8TZ5E8Wlkud4

[7] Drobnjak, S., Amović, M. and Gigovic, L. (2016) Central geospatial database analysis of the quality of road infrastructure data. Geodetski Vestnik, 60, 269.

https://www.researchgate.net/publication/305378070_Central_geospatial_database_ analysis_of_the_quality_of_road_infrastructure_data

[8] Lu, J., Wang, L., Xiao, Q. and Shang, Y. (2015) Incremental Mining of Co-Locations from Spatial Database. 2015 12th International Conference on Fuzzy Systems and Knowledge Discovery (FSKD), Zhangjiajie, 15-17 August 2015, 612-617.

https://ieeexplore.ieee.org/document/7382013

[9] Andrea, D., Melazzi, N.B., Orru, M., Paolillo, R. and Rossi, G. (2016) OpenGeoBase: Information Centric Networking Meets Spatial Database Applications. 2016 IEEE Globecom Workshops (GC Wkshps), Washington, 4-8 December 2016, 1-7. https://ieeexplore.ieee.org/document/7848988/

[10] Michaelis, C. and Ames, D. (2008) Web Feature Service (WFS) and Web Map Service (WMS). In: Shekhar, S. and Xiong, H., Eds., Encyclopedia of GIS, Springer, Boston. https://doi.org/10.1007/978-3-319-23519-6_1480-2

[11] Foresti, G.L., Micheloni, C., Snidaro, P. and Ellis, T. (2005) Active Video-Based Surveillance System: The Low-Level Image and Video Processing Techniques Needed For Implementation. IEEE Signal Processing Magazine, 22, 25-37. https://doi.org/10.1109/MSP.2005.1406473

[12] Ivetić, D., Mihić, S. and Markoski, B. (2010) Augmented AVI Video File for Road Surveying. Computers \& Electrical Engineering, 36, 169-179.

https://doi.org/10.1016/j.compeleceng.2009.08.003 